\title{
FAKTOR YANG BERHUBUNGAN DENGAN PEMILIHAN ALAT KONTRASEPSI IUD PADA PASANGAN USIA SUBUR DI PUSKESMAS BANJAREJO KOTA MADIUN
}

\section{Factors Related To With Selection Of lud Contraceptives In Couples Of Reproductive Age At Puskesmas Banjarejo, Madiun City}

\section{Reky Galih Perwira ${ }^{\text {** }}$ \\ Riska Ratnawati ${ }^{2}$ \\ Zaenal Abidin ${ }^{3}$}

\author{
*IStikes Bhakti Husada Mulia \\ Madiun, Kota Madiun,Jawa \\ Timur,Indonesia \\ 2Stikes Bhakti Husada Mulia \\ Madiun, Kota Madiun,Jawa \\ Timur,Indonesia \\ 3Stikes Bhakti Husada Mulia \\ Madiun, Kota Madiun,Jawa \\ Timur,Indonesia
}

*email: rekygalihp@gmail.com

Kata Kunci:

Alat Kontrasepsi IUD

Pasangan Usia Subur

\section{Keywords:}

IUD Contraception

Couple of Reproductive Age

\begin{abstract}
Abstrak
Intra Uterine Device (IUD) salah satu alat kontrasepsi efektif untuk mencegah atau menunda kehamilan, selain efektif, IUD mempunyai kelebihan lain yaitu mempunyai jangka waktu pemakaian yang lama.Tujuan dari penelitian ini adalah menganalisis faktor yang berhubungan dengan pemilihan alat kontrasepsi IUD pada pasangan usia subur. Dalam penelitian ini, peneliti menggunakan penelitian kuantitatif deskriptif sebagai pendekatan. Metode penelitian yang digunakan adalah survey analitik sedangkan jenis penelitiannya cross sectional. Jumlah populasi sebanyak 90respondendengan jumlah sampel sebanyak 73responden. Hasil uji chi-square menunjukkan bahwa terdapat hubungan yang signifikan variabel independen yaitu pengetahuan $(p$-value $=0,019)$, penerimaan informasi $K B(p$-value $=0,027)$ dan dukungan suami ( $\mathrm{p}$-value $=0,010$ ) dengan pemilihan alat kontrasepsi IUD pada pasangan usia subur. Peneliti menyimpulkan bahwa ada hubungan antara pengetahuan, penerimaan informasi KB dan dukungan suami dengan pemilihan alat kontrasepsi IUD pada pasa usia subur.Dari penelitian ini, saran yang disampaikan adalah penelitian ini dapat dijadikan sebagai referensi peneliti selanjutnya. Peneliti berharap kepada peneliti selanjutnya untuk menambah variabel bebas lingkungan dan dukungan tenaga kesehatan.
\end{abstract}

\begin{abstract}
Intra Uterine Device (IUD) is one of the effective contraceptives to prevent or delay pregnancy, besides being effective, the IUD has other advantages, namely having a long period of use.The purpose of this study was to analyze the factors associated with the selection of IUD contraception in couples of reproductive age. In this research, the researcher uses descriptive quantitative research as approach. The research method uses is analytical survey while the type of research is cross sectional. The are 90 population asrespondentswiththe number of samples as 73 respondents. The results of the chi-square test showed that there was a significant relationship between independent variables, namely knowledge ( $p$-value $=0.019$ ), acceptance of family planning information $(p$-value $=0.027$ ) and husband's support ( $p$-value $=0.010)$ with the choice of IUD contraception in couples of reproductive age.The researcher concludes that there is a relationship between knowledge, acceptance of family planning information and husband's support with the choice of IUD contraception at the couplesof reproductive age.From this research, the suggestion is that this research can be uses as a reference for further researchers. The researcher hopes that further researchers will add the independent variables of the environment and the support of health workers.
\end{abstract} Palangkaraya. This is Open Access article under the CC-BY-SA License (http://creativecommons.org/licenses/by-sa/4.0/). DOI: https://doi.org/10.33084/jsm.vxix.xxx.

\section{PENDAHULUAN}

Keluarga berencana tercantum ke dalam 17 Tujuan Pembangunan Berkepanjangan ataupun Sustainable Development Goals (SDGs) yang telah disepakati oleh negara- negara anggota PBB tahun 2015. Keluarga berencana terdapat pada tujuan guna menjamin kehidupan yang sehat serta menunjang kesejahteraan untuk seluruh usia. Sasaran ke- 3 poin 7 dalam tujuan 
tersebut mengatakan kalau pada tahun 2030, pemerintah menjamin akses universal terhadap layanan perawatan kesehatan seksual serta reproduksi, termasukuntuk keluarga berencana, informasi serta pendidikan, dan integrasi kesehatan reproduksi ke dalam strategi program nasional(Armida Salsiah Alisjahbana, 2018).

Pemerintah sudah menetapkan kebijakan keluarga berencana melalui penyelenggaraan program keluarga berencana. Peraturan Pemerintah No 87 Tahun 2014 Tentang Perkembangan Kependudukan serta Pembangunan Keluarga, Keluarga Berencana, serta Sistem Informasi Keluarga mengatakan bahwa program Keluarga Berencana (KB) merupakan upaya mengendalikan kelahiran anak, jarak serta usia ideal melahirkan, mengendalikan kehamilan, melalui promosi, perlindungan, serta bantuan sesuai dengan hak reproduksi guna mewujudkan keluarga yang berkualitas. Pengaturan kehamilan merupakan upaya untukmembantupasangan suami istri untuk melahirkan pada usia yang ideal, mempunyai jumlah anak, serta mengendalikan jarak kelahiran anak yang ideal dengan menggunakan metode, perlengkapan, serta alat kontrasepsi(Anonim, 2014).

Pemakaian alat kontrasepsi dapat dilakukan dengan menggunakan dua metode yaitu Metode Kontrasepsi Jangka Panjang (MKJP) dan Metode Kontrasepsi Jangka Pendek (non-MKJP). Peningkatan penggunaan Metode Kontrasepsi Jangka Panjang (MKJP) merupakan salah satu sasaran dari lima sasaran strategis yang telah ditetapkan oleh Badan Kependudukan dan Keluarga Berencana Nasional (BKKBN) dalam rangka pencapaian tujuan strategis. Metode Kontrasepsi Jangka Panjang (MKJP) mempunyai tingkat efektivitas yang jauh lebih tinggi dibandingkan dengan Metode Kontrasepsi Jangka Pendek (non-MKJP) dalam hal pencegahan atau penunda kehamilan(BKKBN, 20I7). Jenis metode yang termasuk ke dalam Metode Kontrasepsi Jangka Panjang (MKJP) adalah kontrasepsi mantap pria dan wanita (tubektomi dan vasektomi),
Implant dan Intra Uterine Device (IUD). Intra Uterine Device (IUD) merupakan salah satu MKJP yang paling sedikit menimbulkan keluhan atau masalah dibandingkan dengan pil, suntik, serta susuk KB(Ariffin, 20|4).

Intra Uterine Device (IUD) mempunyai tingkat efektivitas yang jauh lebih tinggi dibandingkan dengan non-MKJP dalam hal pencegahan atau penunda kehamilan. Efektivitas IUD disebutkan bahwa dari 0,6 0,8 kehamilan/100 perempuan dalam satu tahun pertama terdapat satu kegagalan dalam 125 - 170 kehamilan. IUD merupakan alat kontrasepsi jangka panjang yang reversible, pemakaian IUD diantaranya tidak menimbulkan efek sistemik, efektivitas cukup tinggi, dan dapat digunakan oleh semua wanita di semua usia reproduksi selama wanita tersebut tidak mempunyai kontra indikasi dari IUD(Ariffin, 20I4).

Menurut Badan Kependudukan dan Keluarga Berencana (BKKBN), Indonesia mempunyai $K B$ aktif di antara PUS pada tahun 2018 sebesar 63,27\% sedangkan pada tahun 2019 sebesar 62,5\%, yang mengalami penurunan sebesar $0,77 \%$. Sementara target RPJMN yang ingin dicapai pada tahun 2019 sebesar 66\%. Akseptor KB IUD di Indonesia merupakan terbanyak urutan kedua jika dibandingkan dengan MKJP lainnya, pengguna implant sebesar II,20\%, IUD sebesar 10,61\%, MOW sebesar 3,54\%, dan MOP sebesar 0,54\%(Profil Kesehatan Indonesia, 2019).

Provinsi Jawa Timur peserta KB aktifdi antara PUS pada tahun 2018 sebesar $76,62 \%$ sedangkan pada tahun 2019 sebesar 74,94\%, dengan demikian terjadi penurunan $1,68 \%$ peserta KB aktif. Penggunaan akseptor KB IUD di Provinsi Jawa Timur pada tahun 2018 sebesar $9,2 \%$ sedangkan pada tahun 2019 sebesar $3,89 \%$, dengan demikian terjadi penurunan 5,31\% pengguna akseptor KB IUD(Profil Kesehatan Provinsi Jawa Timur, 2019).

Berdasarkan data dari Profil Kesehatan Kota Madiun, jumlah PUS di Kelurahan Banjarejo yaitu sebanyak 2.466 orang. Pada tahun 2018 pengguna alat 
kontrasepsi IUD sebesar 38,7\%, sedangkan pada tahun 2019 pengguna alat kontrasepsi IUD sebesar $41,1 \%$ dan tahun 2020 pengguna alat kontrasepsi IUD sebesar 42,1\%. Dengan demikian pengguna alat kontrasepsi IUD dari tahun 2018 sampai dengan tahun 2020 terjadi peningkatan sebesar 3,4\% pengguna alat kontrasepsi IUD(Profil Kesehatan Kota Madiun, 2019).

Melihat tingginya angka peningkatan pengguna alat kontrasepsi IUD telah dilakukan berbagai upaya dari pemerintah yang dapat dilakukan untuk meningkatkan alat kontrasepsi jangka panjang seperti IUD agar dapat menurunkan angka kelahiran di Indonesia. Maka dari itu untuk menciptakan pengetahuan yang baik perlu memotivasi PUS (Pasangan Usia Subur) dengan cara promosi kesehatan dengan pemberian informasi mengenai penggunaan alat kontrasepsi KB dan disertai dengan adanya dukungan suami.

Berdasarkan uraian diatas, maka dengan meningkatnya angka pengguna alat kontrasepsi IUDperlu diadakannya sosialisasi atau penyuluhan tentang pemilihan alat kontrasepsi supaya masyarakat tahu tentang efek samping yang ditimbulkan dari alat kontrasepsi yang diinginkan ataupun yang dipakai saat itu juga. Pemilihan alat kontrasepsi yang tepat merupakan salah satu hal yang perlu diperhatikan oleh masyarakat terutama pada pasangan usia subur, karena masing-masing dari alat kontrasepsi tersebut mempunyai kelebihan dan kekurangan. Dengan adanya teori dasar yang dikembangkan oleh Lawrence Green (1980) dalam (Notoatmodjo, 2012) menjelaskan bahwa perilaku penggunaan alat kontrasepsi IUD pada pasangan usia subur merupakan salah satu faktor yang berhubungan dengan penggunaan alat kontrasepsi IUD. Perilaku dipengaruhi oleh tiga faktor yaitu faktor predisposisi (predisposing factors) yang terdiri dari pengetahuan, faktor pemungkin (enabling factors)yang terdiri penerimaan informasi $K B$, dan faktor penguat (reinforcing factors) terdiri dari dukungan suami.Untuk menjawab persoalan tersebut peneliti ingin melihat dan mengukur seberapa besar keberhasilan penggunaan alat kontrasepsi IUD pada pasangan usia subur dilihat dari variabel yang telah peneliti siapkan untuk diukur dalam pelaksanaannya, variabel yang ingin dilihat dalam mengukur penggunaan alat kontrasepsi IUD pada pasangan usia subur adalah sebagai berikut pengetahuan, penerimaan informasi KB, dan dukungan suami. Hal ini lah yang melatar belakangi peneliti untuk menganalisis Faktor Yang Berhubungan Dengan Pemilihan Alat Kontrasepsi IUD Pada Pasangan Usia Subur di Puskesmas Banjarejo.

\section{METODOLOGI}

Penelitian ini merupakan jenis penelitian kuantitatif dengan desain penelitian metode survei analitik dengan pendekatan cross sectional. Populasi dalam penelitian ini adalah semua pasangan usia subur yang memakai IUD yang bertempat tinggal di Kelurahan Banjarejo wilayah UPTD Puskesmas Banjarejo. Jumlah populasi sebesar 90 orang dan menggunakan sampel sebanyak 73 orang. Teknik sampling menggunakan simple random sampling dengan kriteria inklusi yaitu responden dari pasangan usia subur yang berumur 15-49 tahun yang tercatat pada catatan medik Puskesmas Banjarejo sebagai akseptor KB dan responden merupakan pasangan usia subur yang menggunakan IUD dan pada saat penelitian masih menggunakan IUD.

Variabel independent dalam penelitian ini yaitu pengetahuan, penerimaan informasi $K B$, dan dukungan keluarga , sedangkan variabel dependent dalam penelitian ini yaitu pemilihan alat kontrasepsi IUD pada pasangan usia subur. Teknik pengumpulan data menggunakan kuesioner dan wawancara kepada responden. Teknik analisa data menggunakan analisa bivariat dengan uji chi-square bertujuan untuk menyimpulkan atau tidaknya hubungan antara dua variabel kategorik.

\section{HASIL DAN PEMBAHASAN}


Dari hasil penelitian dari uji chi-square terdapat 3

kontrasepsi IUD pada pasangan usia sabar. variabel mempunyai pengaruh pada pemilihan alat

Tabel I. Hubungan Pengetahuan, Penerimaan Informasi KB, Dukungan Suami Terhadap Pemilihan Alat Kontrasepsi IUD Pada Pasangan Usia Subur.

\begin{tabular}{ccc}
\hline Variabel & p-value & Keterangan \\
\hline Pengetahuan & 0,019 & Adanya hubungan pengetahuan dengan pemilihan alat kontrasepsi IUD
\end{tabular}
pada pasangan usia subur ini sesuai dengan dengan teori (Notoatmodjo, 2012) menyatakan bahwa pengetahuan merupakan hasil dari tahu, dan ini terjadi setelah orang melakukan pengindraan terhadap suatu objek tertentu. Perilaku seseorang akan lebih utuh apabila didasari oleh pengetahuan.Pengetahuan diperlukan sebagai dorongan dalam menimbulkan sikap dan perilaku terutama perilaku dalam memilih alat kontrasepsi. Peranan pengetahuan ber-KB diarahkan pada pemahaman pasangan usia subur tentang umur yang sehat untuk hamil dan melahirkan, jarak kehamilan yang terlalu berisik, serta jumlah anak yang ideal demi mencapai keluarga sejahtera dan bahagia. Hal ini juga sejalan dengan penelitian(Desy, 2010)menyatakan bahwa ada hubungan yang signifikan antara pengetahuan dengan pemilihan alat kontrasepsi IUD karena mayoritas responden memiliki pengetahuan yang baik. Penelitian (Program et all, 20I3) juga menyatakan bahwa adanya hubungan antara pengetahuan dengan pemilihan alat kontrasepsi IUD karena disebabkan pengetahuan responden yang baik. Penelitian ini juga sejalan dengan (Sari, 2016) bahwa ada hubungan pengetahuan ibu terhadap pemilihan alat kontrasepsi KB IUD hal ini disebabkan pengetahuan menjadi dasar dalam berperilaku dan mepersepsikan sesuatu. Pengetahuan yang benar akan mempertinggi minat menggunakan KB.

Berdasarkan hasil penelitian, sebagian besar responden pengetahuan kurang baik dengan persentase 58,9\% dikarenakan keyakinan atau kepercayaan memakai alat kontrasepsi IUD dan juga responden kebanyakan coba-coba karena ada teman, saudara yang memakai alat kontrasepsi IUD sehingga responden tertarik untuk memakai alat kontrasepsi IUD tersebut. Di samping itu, alat kontrasepsi IUD memiliki kelebihan yang unggul seperti efek samping yang sedikit, IUD merupakan metode kontrasepsi jangka panjang, serta kebanyakan responden yang memakai alat kontrasepsi IUD haid jadi lancar dan teratur.

Penerimaan Informasi $\quad 0,008$ $\mathrm{KB}$
Hasil penelitian ini sesuai dengan teori (Widaningsih, 2007)bahwa ada hubungan penerimaan informasi KB pada penilihan alat kontrasepsi dikarenakan informasi yang diberikan pada calon atau akseptor KB harus disampaikan secara lengkap, jujur, benar tentang metode kontrasepsi yang digunakan, kemungkinan efek samping, kontraindikasi dari metode atau alat kontrasepsi tersebut. Informasi mengenai berbagai metode alat kontrasepsi, menjadikan seseorang memiliki pengetahuan baik karena lebih tahu apa yang sebaiknya dilakukan untuk menjarangkan kelahiran anak dan juga membantu seseorang untuk menentukan pilihan dalam alat kontrasepsi yang tepat. Penelitian ini sejalan dengan (Rahma, 20II) mengatakan bahwa ada hubungan antara penerimaan informasi KB pada pemilihan alat kontrasepsi IUD.

Berdasarkan hasil penelitian, sebagian besar responden penerimaan informasi KB kurang baik dengan persentase 56,2\% dikarenakan responden sebenarnya mengetahui tentang alat kontrasepsi yang digunakan tetapi responden kurang akan informasi tentang KB yang diberikan oleh bidan ataupun petugas kesehatan, penyampaian informasi KB tidak diberikan secara teratur (setiap I bulan sekali) sehingga responden kebingungan akhirnya memilih untuk coba-coba sehingga informasi KB yang didapatkan pun kurang jelas dan juga responden kurang mengeksplor lagi apa saja alat kontrasepsi sehingga informasi yang 
didapatkan hanya dari petugas kesehatan.

Dukungan Suami
0,004

Menurut (Friendman, 2008) mengatakan faktor yang mempengaruhi dukungan termasuk didalamnya adalah tingkat pengetahuan. Keyakinan seseorang terhadap adanya dukungan terbentuk oleh variabel intelektual yang terdiri dari pengetahuan, latar belakang pendidikan dan pengalaman masa lalu. Kemampuan untuk memahami faktor-faktor yang berhubungan dengan penyakit menggunkan pengetahuan tentang kesehatan untuk menjaga kesehatan dirinya. Hasil penelitian ini sejalan dengan (Bernadus, 2013)mengatakan bahwa ada hubungan dukungan suami terhadap pemilihan alat kontrasepsi KB sehingga persetujuan pasangan yang mendukung lebih berpeluang dalam memilih alat kontrasepsi daripada pasangan yang tidak mendukung.Penelitian (Dwi, 2010)mengemukakan bahwa persetujuan suami berperan penting dalam pemasangan alat kontrasepsi IUD membutuhkan kerjasama dengan suami karena alasan takut benangnya menganggu saat bersenggama. Dukungan suami sangat diperlukan untuk pengambilan keputusan dalam ber-KB karena kenyataan yang terjadi di masyarakat bahwa apabila suami tidak mengijinkan atau tidak mendukung hanya sedikit ibu yag berani untuk memasang alat kontrasepsi tersebut.

Berdasarkan hasil penelitian, sebagian besar responden dengan dukungan suami tidak mendukung dengan presentase $58,9 \%$ dikarenakan responden mengatakan sebenarnya dukungan suami itu sangat penting untuk memotivasi dan mensupport istri dalam pemilihan alat kontrasepsi yang akan digunakan. Tetapi kebanyakan suami sulit untuk mengantar istri pergi kontrol KB ke dokter, bidan, dan layanan kesehatan, suami tidak bersedia menemani istri saat konsultasi $K B$, suami sering menakut-nakuti istri tentang efek samping dari KB, serta suami lebih menginginkan istri memilih alat kontrasepsi yang diinginkan agar cocok dengan kondisinya dan lebih sesuai sedangkan suami berpikir jika memakai alat kontrasepsi yang sesuai tidak akan menganggu saat hubungan seksual.

\section{KESIMPULAN}

Berdasarkan hasil penelitian dan pembahasan dalam penelitian ini tentang faktor yang berhubungan dengan pemilihan alat kontrasepsi IUD pada pasangan usia subur di Puskesmas Banjarejo Kota Madiun dapat diambil kesimpulan sebagai berikut Ada hubungan antara pengetahuan dengan pemilihan alat kontrasepsi IUD pada pasangan usia subur di Puskesmas Banjarejo Kota Madiun, Ada hubungan antara penerimaan informasi $K B$ dengan pemilihan alat kontrasepsi IUD pada pasangan usia subur di Puskesmas Banjarejo Kota Madiun dan Ada hubungan antara dukungan suami dengan pemilihan alat kontrasepsi IUD pada pasangan usia subur di Puskesmas Banjarejo Kota Madiun. Saran pada peneliti selanjutnya agar dapat lebih meniliti lagi variabel yang berhubungan dengan pemilihan alat kontrasepsi IUD pada pasangan usia subur dengan menambahkan variabel bebas lingkungan, dukungan tenaga kesehatan sehingga hasil yang diperoleh lebih mendalam.

\section{UCAPAN TERIMA KASIH}

Terimakasih saya ucapkan kepada Stikes Bhakti Husada Mulia Madiun serta Wilayah Kerja UPTD Puskesmas Banjarejo yang telah membantu dan mensupport dalam melakukan penelitian.

\section{REFERENSI}

I. Armida Salsiah Alisjahbana, E. M. (20/8). Tujuan Pembangunan Berkelanjutan Di Indonesia: Konsep Target dan Strategi Implementasi. UNPAD Press.

2. Anonim. (20/4). Peraturan Pemerintah Republik Indonesia Nomor 87 Tahun 2014 tentang 
Perkembangan Kependudukan dan Pembangunan Keluarga, Keluarga Berencana, dan Sistem Informasi Keluarga. In Anim. Behav (pp. 283-29I)

3. BKKBN. (2017). Laporan Akuntabilitas Kinerja Instansi Pemerintah. In Arch. Pharm (pp. 367-372).

4. Ariffin (ed). (20|4). Buku Panduan Praktis Pelayanan Kontrasepsi. PT Bina Pustaka Sarwono Prawirohardjo.

5. Profil Kesehatan Indonesia. (2019). Profil Kesehatan Indonesia Tahun 2019. Kementrian Kesehatan Repoblik Indonesia (Vol. 42).

6. Profil Kesehatan Provinsi Jawa Timur. (2019). Profil Kesehatan Provinsi Jawa Timur 2019. Profil Kesehatan Provinsi Jawa Timur, 25-26.

7. Profil Kesehatan Kota Madiun. (2019). Profil Kesehatan Kota Madiun. Profil Kesehatan Kota Madiun.

8. Notoatmodjo. (20/2). Metodologi Penelitian Kesehatan. In Jakarta: PT.Rineka Cipta.

9. Program et all, S. (20|3). Faktor-Faktor Yang Berhubungan Dengan Penggunaan Alat Kontrasepsi Dalam Rahim Di Wilayah Kerja Puskesmas Kecamatan Pasar Rebo Jakarta Timur.

10. Widaningsih. (2007). Hubungan Antara Pemberian Informasi KB Dengan Pemilihan Alat Kontrasepsi. Jurnal Kesehatan Komunitas.

II. Rahma, A. (20II). Faktor-Faktor Yang Berhubungan pada Pemilihan Alat Kontrasepsi IUD. Jurnal Universitas Diponegoro

12. Friendman. (2008). Faktor Yang Mempengaruhi Dukungan Terhadap Pemilihan Alat Kontrasepsi KB.

13. Bernadus, J. (20|3). Faktor-Faktor Yang Berhubungan Dengan Pemilihan Alat Kontrasepsi IUD Bagi Akseptor KB. Jurnal Ilmiah Keperawatan, I.

14. Dwi, S. (20/0). Hubungan Dukungan Suami Terhadap Pemilihan Alat Kontrasepsi KB IUD. Jurnal IImu Kesehatan UMP.

15. Desy. (2010). Faktor Yang Berhubungan Dengan Pemilihan Alat Kontrasepsi IUD. Jurnal Kesmadaska, I(I).

16. Sari, E. (2016). Faktor Yang Berhubungan Dengan Minat Ibu Terhadap Penggunaan Alat Kontrasepsi
IUD. Jurnal Universitas 'Aisyiyah Yogyakarta. 